\title{
Liver transplantation in Brazil: the urgent need of a new allocation system for the exceptions in MELD score
}

Andraus W. Liver transplantation in Brazil: the urgent need of a new allocation system for the exceptions in MELD score. Arq Gastroenterol. 2020;57:1-2.

The Model for End-stage Liver Disease (MELD) was adopted for liver transplant allocation in USA in 2002, and in Brazil in 2006. The rational of this change was to prioritize the sicker patients, promote a better use of grafts, a less mortality in the waiting list, and a better allocation system with more equality and justice. The model was adopted worldwide due to its characteristics of being simple and a good predictor of mortality for patients with severe chronic liver disease. However, there are some diseases in which the patients need to be transplanted but their score would never reach a transplantable number. For this reason, many countries proposed extra points for patients that do not fit the MELD formula - the "MELD exceptions". The number of extra points and the criteria are not standardized in all countries and they are somehow subjective ${ }^{(1)}$.One example is the HCC patient. In most countries following a restrictive criteria (ex: Milan criteria) patients with $\mathrm{HCC}$ receive extra points in MELD score in order to be transplanted in a time that minimize the chance of losing such criteria or dying in the waiting list. The problem is the big difference in terms of transplantable MELD score between the regionals inside the country (states), the ABO blood types, the MELD exceptions themselves, and also the dynamic changes in the MELD required to be transplanted over time.

The MELD needed to transplant a patient is different for each $\mathrm{ABO}$ blood type, much higher in types $\mathrm{O}$ and $\mathrm{A}$, where the ratio recipients/donors is much higher. Latin America is a very heterogeneous region regarding transplant rates. In Brazil, there is also a big difference between the regionals, São Paulo for example has a big waiting list, and a need of a high MELD to be transplanted, on the other hand, some states in Brazil have a very short waiting list and they transplant patients with low MELD, often less than $20^{(2)}$. Another fact that is not taken into account is that the rate of donation per million in Brazil has increased significantly in the last fourteen years, since the MELD was adopted, and the extra points given for the MELD exceptions kept the same. Furthermore, the difference in mortality rate in waiting list between all the MELD exceptions is not considered, as they receive the same score after approved. In summary, the actual policy does not give an equal access to liver transplantation for all the patients in the country, especially when we talk about different states and MELD exceptions.

The shortage of liver grafts, the high mortality in the waiting list $\mathrm{t}^{(3)}$ and the high cost of patient preparation and maintenance before transplant ${ }^{(4)}$, brings the importance of searching for maximize the use of grafts and try to reduce the wait list mortality. Patients with HCC often have a lower functional MELD score and a better nutritional status, thus they could receive an expanded criteria organ, however, the current situation frequently put them first in line and they get the best grafts, and the expanded criteria organs are refused for sicker patients.

When we give the same extra points for so different regionals, different conditions, different blood types, we generate big discrepancies, giving privileges to certain patients and neglecting others. One example is the big advantage of HCC patients over the other chronic liver diseases in terms of transplantation, especially in states where the MELD score needed for being transplanted is much lower ${ }^{(5)}$. The issue becomes even worse when HCC patients with higher socioeconomical levels migrate from a "big list state" to a "small list state", where they are transplanted very fast and probably before than a local chronic disease patient, increasing even more this discrepancy.

The discussion about the advantage of HCC patients and other MELD exceptions over the chronic disease patients has been brought in Brazilian meetings and publications ${ }^{(5,6)}$, nevertheless it has not resulted in any effective measure to improve the system. Instead, frequently the discussions come out with wrong conclusions, as that we cannot expand Milan Criteria in Brazil, even for HCC patients with similar survival and good tumor biology, because HCC patients have already an "advantage". It is important to highlight that the patients beyond Milan Criteria and good indication for transplant cannot be blamed because of "our decision", it is our fault, since we gave an "advantage" to the Milan criteria patients, not them.

The right conclusion is simple: the extra points given for exceptions in MELD score allocation system cannot be the same for all conditions because they are different in outcome and mortality, neither for different blood types, different regionals, and they should't be the same for a long period, since the transplantable MELD score changes over time. We as doctors know the theory, but we are not specialists in this field. We need mathematicians to create a dynamic formula that takes into account the transplantable MELD score and the mortality rate in the waiting list for each specific condition and circumstances during a period of time, one year for example. Ourselves and our transplant system need to be less sluggish regarding the revision and changes of the rules and policies that drive transplant allocation in Brazil.

Wellington ANDRAUS*

* Corresponding author: Wellington Andraus, MD, PhD. Universidade de São Paulo (HC FMUSP), Departamento de Gastroenterologia, Transplante de Órgãos do Aparelho Digestivo, São Paulo, SP, Brasil. Orcid: 0000-0002-5162-138X. E-mail: wellingtonandraus@gmail.com 
Andraus W. Transplante de fígado no Brasil: necessidade urgente de um novo sistema de alocação para as exceções no escore MELD. Arq Gastroenterol. 2020;57:1-2.

\section{REFERENCES}

1. Tschuor C, Ferrarese A, Kuemmerli C, Dutkowski P, Burra P, Clavien PA, et al. Allocation of liver grafts worldwide - Is there a best system? J Hepatol. 2019;71:707-18.

2. Andraus W. Barriers and Limitations to Access to Liver Transplantation in Latin America. Clin Liver Dis (Hoboken). 2019;13:36-8.

3. Martino RB, Waisberg DR, Dias APM, Inoue VBS, Arantes RM, Haddad LBP, et al. Stratifying Mortality in a Model for End-Stage Liver Disease Waiting List: A Brazilian Single-Center Study. Transplant Proc. 2018;50:758-61.

4. Rodríguez S, Motta FD, Balbinoto Neto G, Brandão A. Evaluation and selection of candidates for liver transplantation: an economic perspective. Arq Gastroenterol. 2020;57:31-8.

5. Rodríguez S, Fleck AM, Mucenic M, Marroni C, Brandão A. Hepatocellular carcinoma patients are advantaged in the current Brazilian liver transplant allocation system. A competing risk analysis. Arq Gastroenterol. 2020;57:19-23.

6. Ferre-Aracil C, Lledó JL, Aguilera L, Garcia-Paredes A, Rodríguez-Santiago E, Graus J, et al. Current allocation policy is favorable for patients with hepatocellular carcinoma waiting for liver transplantation. Dig Liver Dis. 2018;50:1345-50. 